\title{
Miocarditis aguda tras una infección por el virus de la varicela-zóster en un adolescente inmunocompetente: una complicación poco frecuente
}

\author{
Acute myocarditis following varicella zoster infection in an immunocompetent \\ adolescent: An uncommon complication
}

\author{
Dra. Emine Azak y Dr. Ibrahim I. Cetin ${ }^{a}$
}

\begin{abstract}
RESUMEN
La miocarditis es una complicación grave de la infección por el virus de la varicela-zóster. Un varón de 15 años ingresó a la sala de emergencias debido a dolor torácico, taquicardia e hipotensión. En el electrocardiograma se observó taquicardia sinusal. Los biomarcadores cardíacos estaban elevados. En el ecocardiograma senotóhipocinesia apical, septal, einferolateral del ventrículo izquierdo e insuficiencia mitral. Los anticuerpos IgM en suero para el virus de la varicela-zóster eran positivos. El paciente recibió el alta sin secuelas.

Palabras clave: adolescente, miocarditis, virus de la varicela-zóster.
\end{abstract}

http: / / dx.doi.org/10.5546/ aap.2020.eng.e284

Texto completo en inglés:

http: / / dx.doi.org/10.5546/ aap.2020.eng.e284

Cómo citar: Azak E, Cetin II. Miocarditis aguda tras una infección por el virus de la varicela-zóster en un adolescente inmunocompetente: una complicación poco frecuente. Arch Argent Pediatr 2020;118(3):e284-e287.

La miocarditis aguda es una causa importante de cardiopatía adquirida en la población pediátrica a nivel mundial. Se han mencionado diversos virus, incluido el virus de la varicela-zóster, como parte de su etiología. Sin embargo, desde la implementación global de la vacunación, los informes de miocarditis por el virus de la varicelazóster han sido esporádicos. ${ }^{1-5}$ Hasta donde

a. Departamento de Cardiología Pediátrica, Universidad de Ciencias de la Salud, Hospital de Formación e Investigación en Salud Infantil y Enfermedades Pediátricas, Hematología y Oncología, Ziraat Mah, Ankara, Turquía.

E-mail address:

Dra. Emine Azak: azakemi@gmail.com

Financiamiento: Ninguno.

Conflicto de intereses: Ninguno que declarar.

Recibido: 8-3-2019

Aceptado: 28-10-2019 sabemos, se informaron solo unos pocos casos de miopericarditis por el virus de la varicela-zóster, con mayor frecuencia en los niños y, raramente, en los adultos inmunocompetentes. Presentamos un caso de miocarditis por el virus de la varicelazóster con desarrollo típico y recuperación rápida y completa en un adolescente que, por lo demás, era sano.

\section{PRESENTACIÓN DE UN CASO}

Un paciente de 15 años que, por lo demás, era sano ingresó a nuestro hospital con dolor torácico grave, palpitaciones y fiebre. No tenía antecedentes médicos de enfermedades graves ni antecedentes familiares de enfermedad cardiovascular. Cinco días antes del ingreso, el paciente comenzó con febrícula acompañada de tos, disnea y dolor torácico. Unas semanas antes, había estado en contacto con un niño que tenía varicela. El paciente había sido vacunado contra la varicela. En el examen físico, se observaron exantemas vesiculopapulosos secos en el tronco, y no presentaba soplos audibles ni roces pericárdicos. La presión arterial era de $90 / 60 \mathrm{mmHg}$ y la temperatura corporal era de $37,7^{\circ} \mathrm{C}$. En el electrocardiograma (ECG), se observó taquicardia sinusal sin supresión del voltaje ni elevación patológica del segmento ST o inversión patológica de la onda T (Figura 1). Según los análisis de laboratorio, tenía un recuento total de leucocitos de 9,5 × 109/1, velocidad de sedimentación globular de $2 \mathrm{~mm} / \mathrm{h}$, proteína C-reactiva de $15 \mathrm{mg} / 1$ (intervalo normal: 0,8$3,1 \mathrm{mg} / 1$ ). La creatina-cinasa miocárdica (CKMB) estaba elevada a $36(0-24 \mathrm{U} / 1)$, al igual que la troponina I cardíaca (TnIc), a 5,94 (0-0,04 mcg/l). La concentración de péptido natriurético $B$ (PNB) también era alta, pasó de $266 \mathrm{pg} / \mathrm{ml}$ a $469 \mathrm{pg} /$ $\mathrm{ml}(0-70 \mathrm{pg} / \mathrm{ml}) 12$ horas después del ingreso. En la Figura 2, se muestran las concentraciones de CK-MB y TnIc durante la hospitalización. El hemograma completo, la albúmina sérica, la creatinina, la urea, las transaminasas hepáticas, 
la proteína C-reactiva y la velocidad de sedimentación globular estaban dentro de los valores normales. El ensayo de inmunoadsorción enzimática (ELISA) fue positivo para el virus de la varicela-zóster, y las concentraciones de inmunoglobulina $\mathrm{M}$ e inmunoglobulina $\mathrm{G}$ eran altas (índice de 30,5 [índice $>11$ ] y $>53,6 \mathrm{ng} / \mathrm{ml}$ [5-9 UI/ml], respectivamente). Los análisis para detectar el virus de Coxsackie, virus ECHO, influenza A y B, citomegalovirus y virus EspteinBarr fueron negativos. En el ecocardiograma se observaron menor contractilidad ventricular izquierda (acortamiento fraccional del $27 \%$, fracción de eyección del $53 \%$ ), insuficiencia mitral leve, ventrículo izquierdo dilatado e hipocinesia apical inferolateral e inferoseptal. El paciente fue ingresado a la unidad de cuidados intensivos pediátricos y comenzó a recibir un antinflamatorio no esteroideo (ibuprofeno, $15 \mathrm{mg} / \mathrm{kg} /$ día), un inhibidor de la enzima convertidora de la angiotensina (enalapril, 0,1 mg/ kg/día) e inmunoglobulina intravenosa (IgIV, $1 \mathrm{~g} / \mathrm{kg}$ por día durante 2 días). Las concentraciones de TnIc, CK-MB y PNB regresaron a valores normales

FIGURA 1. Electrocardiograma que muestra taquicardia sinusal y segmento ST-T normal al momento del ingreso

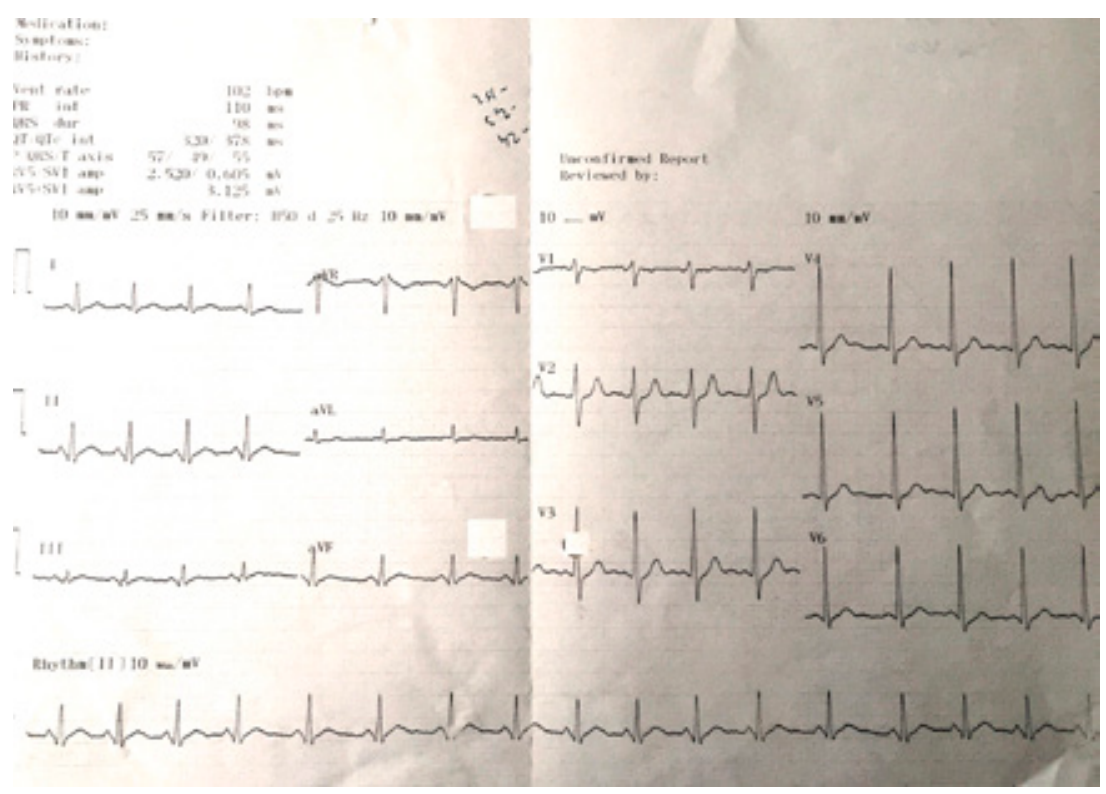

FIGURA 2. Concentración de troponina I y péptido natriurético B durante la hospitalización

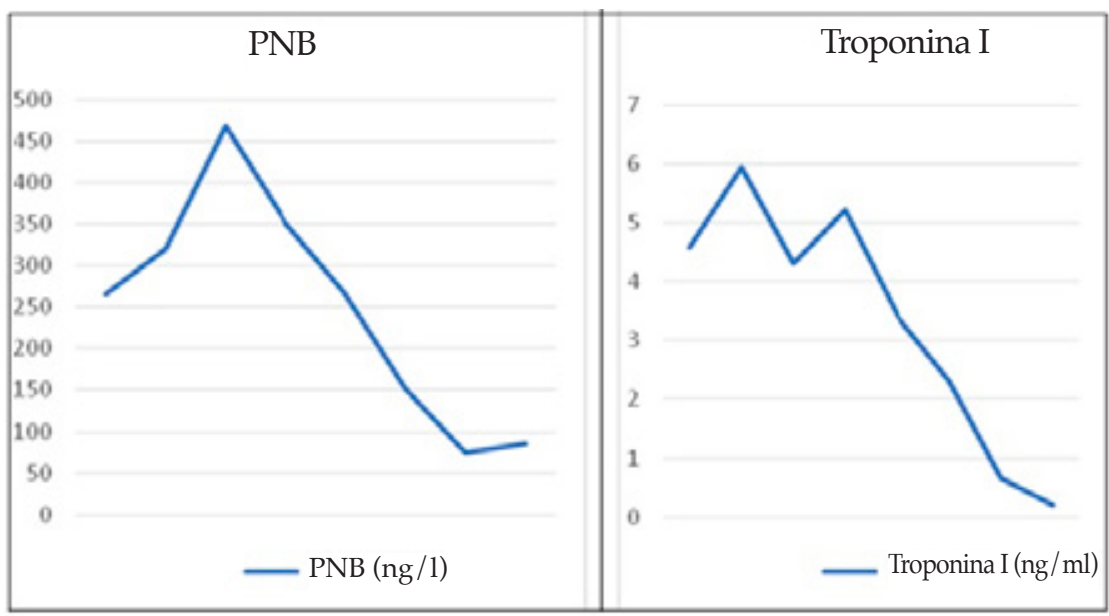


gradualmente (18 U/1, 0,01 mcg/l y $65 \mathrm{pg} / \mathrm{ml}$, respectivamente) $\mathrm{y}$, en un nuevo ecocardiograma, la función cardíaca fue normal (acortamiento fraccional del $38 \%$, fracción de eyección del $68 \%$ ). Después de 10 días de hospitalización, el paciente recibió el alta con instrucciones para que tomara ibuprofeno durante 10 días y enalapril durante 3 meses y para que limitara la actividad física durante 4 a 6 semanas. Además, la concentración de la inmunoglobulina $\mathrm{M}$ (índice de 0,17 ) y de la inmunoglobulina $\mathrm{G}(96,4 \mathrm{UI} / \mathrm{ml})$ para el virus de la varicela-zóster estaba significativamente alta en el seguimiento realizado cuatro semanas después.

\section{DISCUSIÓN}

La miocarditis aguda es una causa importante de cardiopatía adquirida en los pacientes pediátricos. Se han mencionado diversos virus como parte de la etiología. El diagnóstico de miocarditis o miopericarditis es raro durante la infección primaria por el virus de la varicelazóster y esporádico en la reactivación del zóster del virus latente. Se han descripto solo unos pocos casos, con el primer informe sobre el virus de la varicela-zóster publicado en 1953.,1,6-8 Sin embargo, con la administración global de la vacuna contra la varicela, los informes sobre miocarditis por el virus de la varicela-zóster son ahora esporádicos. La infección por el virus de la varicela-zóster es frecuente en la niñez y es posible que una infección subclínica o la miocarditis contribuyan a algunos casos de miocardiopatía dilatada idiopática. ${ }^{5-8}$ El virus de la varicela-zóster es uno de los virus cardiotropos. Sin embargo, la varicela muy raramente está asociada con secuelas cardíacas. Las complicaciones cardiovasculares de la infección por el virus de la varicela-zóster incluyen endocarditis, miocarditis, pericarditis y arritmias. ${ }^{2-5}$ Las secuelas cardíacas de la infección por el virus de la varicela-zóster son raras, pero pueden provocar morbimortalidad si es que ocurren. Dado que la sospecha de miocarditis por varicela en los niños podría estar asociada con complicaciones graves, como insuficiencia cardíaca progresiva, arritmias malignas y muerte súbita, el consenso es que estos pacientes deben recibir cuidados intensivos..$^{7-11}$ La miocarditis asociada con una enfermedad viral constituye un proceso inflamatorio que puede generar daño temporal o permanente en la estructura del miocardio y el sistema de conducción. Las manifestaciones histopatológicas de la miocarditis por varicela son similares a las de otros tipos de miocarditis viral. La presentación clínica de la miocarditis viral puede variar de una evolución asintomática a enfermedad fulminante aguda, como colapso cardiovascular. Sin embargo, en la mayoría de los casos, la miocarditis es subclínica o presenta cambios menores en la onda T observados en el ECG. ${ }^{3-5,9}$

Debido a que esta enfermedad es muy poco frecuente, no existen pautas terapéuticas generalmente aceptadas para el tratamiento de la miocarditis por varicela. Normalmente, el tratamiento de la miocarditis aguda por el virus de la varicela-zóster es sintomático, pero es necesario excluir la presencia de síndrome coronario agudo antes de iniciarlo. La miopericarditis puede imitar el síndrome coronario agudo y la diferencia en la presentación clínica atípica puede ser sutil. Según las publicaciones, en estos casos, se destaca que una angiografía coronaria es la estrategia inicial más segura y prudente. Tras descartar la obstrucción de las arterias coronarias en estos pacientes, el tratamiento de la miopericarditis incluye el manejo hospitalario con antinflamatorios no esteroideos, monitoreo de la función miocárdica y, de ser necesaria, la corrección de la disfunción ventricular izquierda o las arritmias. Una vez que el paciente recibe el alta, se le recomienda que limite la actividad física durante 4 a 6 semanas. ${ }^{2-5}$

El aciclovir es el agente antiviral frecuente para el tratamiento de los adultos y niños inmunocompetentes con infección por el virus de la varicela-zóster; en varios informes, se sugieren sus beneficios clínicos en los adultos con complicaciones por este tipo de infección. Sin embargo, debido a la rareza de la miocarditis por el virus de la varicela-zóster, no se dispone de información para respaldar su eficacia. ${ }^{4-8}$ Drighil y cols. especulan que el aciclovir podría ser beneficioso en la miocarditis por el virus de la varicela-zóster si se presenta durante la etapa de replicación viral en el miocardio. ${ }^{3}$ Como es sabido, la replicación del virus de la varicelazóster suele finalizar entre el tercer y séptimo día de la aparición del exantema vesicular; por lo tanto, no se administró aciclovir a nuestro paciente porque presentaba solo exantemas vesiculares secos. Se requieren análisis de laboratorio para confirmar la infección por el virus de la varicelazóster, en especial cuando la lesión cutánea no es típica ni aparente. El resultado de la prueba ELISA fue positivo para el virus de la varicelazóster, con concentraciones elevadas de IgM e IgG. Tras la infección por el virus de la varicelazóster, los anticuerpos IgG and IgM aparecen 
entre 2 y 5 días después del exantema y muestran las concentraciones más altas a las 2 a 3 semanas. Luego la concentración de anticuerpos $\operatorname{IgM}$ para el virus de la varicela-zóster disminuye rápidamente y no puede detectarse un año después de la infección, y la concentración de anticuerpos IgG disminuye progresivamente, por lo que se observan resultados positivos durante varios años. ${ }^{1,8,11,12}$ En nuestro caso, se sospechó la presencia de miocarditis viral aguda asociada con el virus de la varicela-zóster debido al marcado aumento de la concentración de IgG para el virus de la varicela-zóster 4 semanas después de observar resultados positivos de anticuerpos IgM para el virus de la varicela-zóster. El diagnóstico de miocarditis en este caso se basó en el ecocardiograma, los antecedentes clínicos y la presentación clínica de la infección por el virus de la varicela-zóster, y se confirmó serológicamente mediante la prueba ELISA. El uso de aciclovir, sin embargo, no pareció ser beneficioso.

A modo de conclusión, la miocarditis es una complicación grave de la infección por el virus de la varicela-zóster y la insuficiencia cardíaca podría ser fulminante. Pero la información disponible sobre la miocarditis durante la infección por el virus de la varicela-zóster es limitada. El desarrollo de taquicardia y dolor torácico en los pacientes con varicela debe funcionar como signo de posible miocarditis. Las manifestaciones clínicas de la infección por varicela en los adolescentes podrían no ser visibles al momento del ingreso; por lo tanto, los médicos deben estar al tanto de las posibles complicaciones cardiovasculares de la infección por varicela. En situaciones clínicas atípicas, creemos que es necesario descartar la presencia de infarto de miocardio y síndrome coronario agudo antes de proceder con el tratamiento.

La biopsia cardíaca es la prueba diagnóstica de referencia, pero no suele hacerse en la práctica clínica. ${ }^{9-11}$ La sospecha clínica respaldada por las pruebas serológicas es suficiente para el diagnóstico de la miocarditis por el virus de la varicela-zóster. No existen pautas claras para el tratamiento de los pacientes con miocarditis. Se ha informado que la combinación de aciclovir e IgIV puede salvarles la vida a estos pacientes. ${ }^{11-13} \mathrm{En}$ el tratamiento de nuestro paciente, no incluimos el aciclovir, un inhibidor de la replicación del ADN del virus del herpes. Debido a la rareza de la miocarditis por varicela, no se dispone de datos específicos para respaldar su eficacia para esta indicación en particular. Sin embargo, el aciclovir tiene un beneficio claro en el tratamiento de los pacientes con inmunosupresión y varicela aguda.

El objetivo de este informe es señalar que el virus de la varicela-zóster puede causar miocarditis en la adolescencia, que debe tenerse en cuenta al momento del diagnóstico diferencial, y que el diagnóstico temprano y un tratamiento adecuado pueden ayudar a la recuperación completa.

\section{REFERENCIAS}

1. Abrams D, Derrick G, Penny DJ, Shinebourne EA, et al. Cardiac complications in children following infection with varicella zoster virus. Cardiol Young. 2001; 11(6):647-52.

2. Kao KL, Yeh SJ, Chen CC. Myopericarditis associated with varicella zoster virus infection. Pediatr Cardiol. 2010; 31(5):703-6.

3. Drighil A, Hammiri AE, Belmourida F. Chest Pain in a 17-Year-Old Girl with Chickenpox. Pediatr Ann. 2015; 44(9):359-65.

4. ElikowskiW, MarszałekA, Malek-Elikowska M, GanowiczKaatz T, Mozer-lisewska I. Myopericarditis in a 23 year old male with herpes zoster. Pol Merkur Lekarski. 2016; 40(236):97-101.

5. De A, Myridakis D, Kerrigan M, Kiblawi F. Varicella myopericarditis mimicking myocardial infarction in a 17-year-old boy. Tex Heart Inst J. 2011; 38(3):288-90.

6. Donoiu I, Istratoaie O. Varicella-zoster myocarditis mimicking acute myocardial infarction. Curr Health Sci J. 2014; 40(1):78-80.

7. Waagner DC, Murphy TV. Varicella myocarditis. Pediatr Infect Dis J. 1990; 9(5):360-3.

8. O'Grady MJ, Moylett E. Cardiac-related varicella mortality in childhood: a literature review with clinical experience. Pediatr Cardiol. 2011; 32(8):1241-3.

9. Tsintsof A, Delprado WJ, Keog AM. Varicella zoster myocarditis progressing to cardiomyopathy and cardiac transplantation. Br Heart J. 1993; 70(1):93-5.

10. Alter P, Grimm W, Maisch B. Varicella myocarditis in an adult. Heart. 2001; 85(1):E2.

11. Kelly E, Cullen G, McGurk C. When an MI is not an MI: a case of varicella zoster myocarditis. Cardiology. 2008; 109(3):193-5.

12. Min SW, Kim YS, Nahm FS, Yoo da H, et al. The positive duration of varicella zoster immunoglobulin $\mathrm{M}$ antibody test in herpes zoster. Medicine (Baltimore). 2016; 95(33):e4616.

13. Lu YC, Fan HC, Wang CC, Cheng SN. Concomitant use of acyclovir and intravenous immunoglobulin rescues an immunocompromised child with disseminated varicella caused multiple organ failure. J Pediatr Hematol Oncol.2011; 33(8):e350-1. 